Session 2453

Division 53 Freshman Programs

\title{
Integration of first year English and Introduction to Engineering Design: A Path to Explore the Literacy and Culture of Engineering
}

\author{
Sarah Duerden, Jeanne Garland, Christine Helfers, \& Ronald Roedel \\ Department of English/Department of Electrical Engineering \\ Arizona State University, Tempe, AZ 85287
}

\begin{abstract}
One of the goals of the Foundation Coalition's Freshman Integrated Program for Engineers (FIPE) at Arizona State University is to help students attain a critical awareness of the culture in which they live and work. Therefore, through sustained and ongoing dialogue with the engineering professor, the English teachers in the FIPE program have designed a curriculum that asks students to engage with other perspectives, both cultural and historical, about issues relevant to them as future engineers. As Samuel Florman explains, "[w]ithout imagination, heightened awareness, moral sense, and some reference to the general culture, the engineering experience becomes less meaningful, less fulfilling than it should be." In this first of two semesters, the engineering students explore the rhetorics, literacy, and culture of engineering in the university and in the professional workplace. They are exposed to the historical and cultural background of issues related to engineering, they explore rhetorics of inquiry to discover ways of knowing and thinking in engineering, which leads them to more informed arguments, decisions, and use of language. Through a freshman English class that has been carefully integrated with the engineering curriculum, we are able to help students contextualize, explore, question, and apply concepts learned in engineering to their writing in English.
\end{abstract}

\section{Introduction}

The Freshman Integrated Program in Engineering (FIPE) at Arizona State University, developed through funding partnerships with the National Science Foundation sponsored Foundation Coalition, is a first-year course that integrates engineering, calculus, physics, and English Composition. $^{2}$ We have delivered this set of courses successfully to a class of 72-80 students for the last 7 years. Our integration has involved using the first-year-engineering course (delivered both semesters) as an umbrella so that each of the other courses integrates with engineering. In many versions of engineering coursework, the integration is confined to the scientific course engineering with physics, or math, or both. The Foundation Coalition embodiment also includes first year English composition. In the composition course that has meant that our students have written papers related to engineering that were developed with the help of the engineering professors. However, in the last two years, the Writing Programs at Arizona State University has re-envisioned the first-year writing courses, shifting from a traditional modal approach to a cultural studies approach called the Rhetorics, Literacy, and Culture curriculum. ${ }^{3}$ In this curriculum, we define Rhetorics, Literacy, and Culture in our course description: Rhetoric is 
commonly defined as using language to skillfully articulate and advocate beliefs we assume to be true by addressing an audience we want to persuade. Therefore, rhetorics are competing systems of persuasion. Literacy is the ability to recognize that there are different systems of knowledge and to work with those different systems. These strategies are necessary to negotiate the various cultures that are socially constructed and transmitted behaviors, beliefs, values, and institutions. Because the rules of a culture are known to its people in an almost unconscious way, it's hard for someone entering into a new culture to grasp the rules and their significance. Engineering, both in college and in the workplace has its own culture, and understanding that culture and questioning its assumptions will help you as you work through your degree program and then into the professional world. For the English teachers involved in the delivering the writing classes to students in the FIPE program, this shift allowed us to re-envision our own courses so that we have developed a curriculum that engages students in the rhetoric, literacy, and culture of engineering. As a result of our redesigned curriculum, the FIPE students now contextualize, explore, question, and apply concepts learned in engineering to their writing in English.

\section{Background to Integration with Engineering}

When we first began designing the original integrated English course, we felt strongly, as composition teachers, that we would not integrate by only having students turn in their engineering writing to us. Although this strategy may look appealing at first, and certainly proves to be a useful exercise when we want engineering students to learn to consider how to adapt writing to different audiences, it is insufficient when we consider rhetorical knowledge of discourse communities. As Dorothy Windsor and Patricia Bizzell have pointed out, members of a given discipline use language in ways unique to them, including a particular language, style, and set of discourse strategies. ${ }^{4}$ Therefore, only asking students to take the written discourse they produce for their engineering class and make that readable for the English teachers undermines current theories about discourse communities. Furthermore, because we are English teachers, our technical knowledge is limited, and we may sometimes judge student writing as clear that may in fact be presenting incorrect or inaccurate technical information. Instead, the English teachers and engineering professor agreed that students needed to understand that different rhetorical situations demanded different discourse strategies. Windsor refers to this as the "rhetorical view of writing," in which writers negotiate knowledge between themselves and the readers, rather than simply passing on information. Once novice engineers can define these basic elements of purpose and audience, they can better decide on the appropriate type of writing, its content, and its form. Therefore, because the engineering professor taught engineering discourse strategies in his classes, our students quickly discern that the language, style, and format appropriate for the engineering class is not necessarily appropriate for the English class. Further, since we English teachers had laid the groundwork of rhetorical situation, including audience, purpose, and context in our own classes, the engineering professor could employ those terms in his classes.

Having agreed that each subject would be responsible for generating and grading its own written discourse, we were then able to look for obvious areas of integration. With the help of the engineering professor and the revised curriculum developed by the Writing Programs at Arizona State University, we were able to develop a curriculum that asks first-year students to engage with the rhetorics, literacy, and culture of engineering. Our goal was to present writing as both a 
process within the larger cognitive structure as well as an instrument of learning and communicating within the discipline of engineering. Therefore, we developed a set of related assignments that engage students with inquiry into what it means to be an engineering student today. 5

\section{Contextualizing the Culture of Engineering in the College}

Our first goal in this revised curriculum is to help students understand the culture of engineering within the university. Surveys of students show that many choose engineering because advisors suggest their abilities in math and science make this an ideal career. Of course, abilities in math and science do not necessarily guarantee success in engineering. Therefore, we decided that our first assignment in the composition course should be one that allows students to discover the culture of engineering within the college. The first assignment asks students to analyze their own reasons for choosing engineering. Once they have analyzed their own reasons and understanding of engineering, they are then directed to conduct fieldwork, by interviewing team members within engineering, engineering students outside the program, and then contrasting this information with interviews they conduct with non-engineering students. By the end of the assignment, all students have a better understanding of their own major, their reasons for choosing that major, and how that major will differ from other majors at the university. Coincidentally, this understanding also helps some students adjust from the lower academic expectations of high school to the more demanding expectations of college, and it reminds them, during the first difficult four weeks of adjustment of the semester of why they chose engineering.

\section{Contexualizing the Culture of Engineering in the Workplace}

Our second goal for the revised curriculum is to have students understand what the culture of engineering is in the workplace and how the FIPE program prepares them to enter this culture. For example, although a number of students do enter the program with some knowledge of the team environment of the professional workplace, many students still regard this concept with some doubt, believing that they will be the exception to the standard that most engineers work in teams. Furthermore, a surprising number of students still enter with little team experience. Other concepts they find surprising include the importance of communication skills, particularly written skills, and the notion that once they leave college they will still be learning.

After consultation with the engineering professor, we decided that the best way to engage students with these concepts was to develop an assignment that would engage them with the culture of engineering in the workplace. They were assigned a set of readings that described modern engineering practices, which they were currently practicing in their engineering classes, and then attended a guest lecture given by a young engineer. This engineer described her engineering workplace, including how teams worked in this workplace, communication skills, and so on. Following this guest lecture, the students were then asked to interview a professional engineer they knew (most often a relative) and compare their interview notes with those made during the guest lecture. Finally, the students were asked to construct a profile of their engineer, drawing on all the research they had conducted, to show readers the culture of the modern engineering workplace, the skills engineers use on a daily basis, and the myths and stereotypes about engineering that are simply untrue. 
This assignment not only helps students understand the environment they will one day enter, it also helps them understand the FIPE program and why they are being asked to work in teams. Most students found, for example, that the engineers they interviewed wished they had been enrolled in such a program because they would have been better prepared to enter the workforce. In turn, this helped those students who were having difficulties with the FIPE program adjust to our demands.

\section{Exploration \& Questioning}

By working carefully with the engineering professor, we have also been able to integrate English and engineering in other less obvious ways and so meet our third goal of integration: connections between strategies in subject areas. One of the more successful levels is to have students draw parallels between the tools they use in engineering and the tools they use in writing. One of the first tools engineering students are introduced to in engineering is that of heuristics. Within English, we take that same notion but show students how ancient rhetors described heuristics as a set of systematic questions designed to generate ideas about a topic. ${ }^{6}$ They are a means of discovery or invention. However, instead of using the questions generated by Aristotle's common topics, past/future fact, greater/lesser, and possible/impossible, we devise our own set suggested by the assignment. Thus, through a series of carefully constructed questions, we help students build the content of their papers, constantly reminding them that heuristics work in both engineering and writing. For example, for the assignment that students write exploring the culture of engineering, we ask them to answer the following heuristic questions:

1. Prior to class, answer the following questions:

Establishing your own knowledge

- What do I already know about engineers? What words do I associate with them?

- What kinds of work do I think they do?

- What skills do I think they have to possess? What skills are less important to them? What would surprise me in terms of skills they must possess?

- What are the common misconceptions about engineers? What would most people be surprised to discover?

- How do my views of engineers differ from most people's views?

Questions for your engineer

- Write a list of questions that you will use to interview your own engineer. In addition to discovering what they do at work, the culture of their workplace, the skills they employ on a daily basis, the company for which they work, their position, etc., you may also want to consider what makes them different from the stereotypes. Therefore, you may want to create questions that will allow you to discover that information. You may also want to note details about their lives outside work, their appearance, and so on.

2. During the speaker(s) presentation(s), answer the following:

- Name, Company, Position

- Years of work/overview of career

- Physical appearance

Proceedings of the 2001 American Society for Engineering Education Annual Conference \& Exposition Copyright (C)2001 American Society for Engineering Education 
- Key points discussed

- Least surprising

- Most surprising

- Your dominant impression of the speaker

- Key quotation or paraphrase

3. Composing the Profile

- Look through other sources to find profiles of people. Think about how those profiles are organized (either chronologically or topically). After you have completed the rest of the heuristic questions, you will decide which organizational pattern will work best given your audience and purpose.

Drawing on written research

- List the readings we have done this semester that might help with this assignment and write down what might be useful and why. Remember, some of the readings may be out of date and you can use them to show what the stereotypes are and perhaps suggest why those stereotypes still exist.

- Then look through those readings for useful quotations and write down the quotation and page number

- Search the World Wide Web for any other useful material such as profiles of engineers

Establishing audience \& purpose

- What is my purpose in this profile?

- Who are my readers and what must I do to meet their needs in this profile?

- What have I learned about a professional engineer that I found surprising or new?

- Does that differ from what most people think and how?

- Could I turn that into a thesis?

Using your Interview

- How would I describe this person professionally?

- How would I describe this person physically?

- Should I organize my material topically? If I organize topically, what topics should I focus on?

- Which source deals with each topic?

- If I organize chronologically (a day in the life of), when do I begin? What events or actions do I describe? Shall I include a description of the workplace?

- Should I begin this profile with a striking image or vivid scene, an interesting fact, an anecdote, a question, or a piece of dialogue?

- Should I close this profile with a new image, an anecdote, a piece of dialogue, an interesting fact?

- How can I restate my thesis without repeating the same words that I used in the introduction?

In addition to the deliberate use of tools from engineering, we also ask students to complete a series of readings from their engineering text, Engineering by Design by Gerald Voland ${ }^{7}$ and the text we use as a reader in English, The Introspective Engineer by Samuel Florman ${ }^{1}$. Students are 
asked to write a reading response to each assignment, which are collected and read by the English and the engineering professors. They are asked to summarize the reading and then reflect on the reading, connecting to concepts they have learned in their classes or they have discovered through their research. Both texts help students probe deeper into the culture of engineering. The Florman text in particular, as the title suggests, asks students not only to consider what engineers do, but also to consider their roles and responsibilities in modern society.

\section{Application of Concepts}

The next level of integration is achieved by asking students to take concepts they discover in engineering and write about those in their English papers. In this way, students reinforce their learning in engineering while developing their writing skills. As previously mentioned, collaboration is one important concept that is consistently emphasized in the FIPE program. So in the English class, when students write their first two essays, which explore the culture of the engineering major and the culture of the engineering workplace, they discover the importance of teamwork and methods of collaboration. Students make these discoveries through their assigned readings, guest speakers, and interview data that they have gathered. One guest speaker emphasized that learning teamwork in college leads to effective collaboration in the workplace. In addition, she remarked that such experiences also helps engineers become effective mentors. In their research, students also learn the various roles that teammates hold, such as task manager and devil's advocate. When students hear about the importance of teamwork from such a variety of sources, they recognize that this concept is not just a minor point or just schoolroom "group work." In English, we took the concept of collaboration beyond a writing topic and had students use collaborative writing to develop a team paper for their last assignment, which was a causal analysis of an engineering failure. In this way, students had to use effective team skills to write about the engineering failure (which ironically often was related to a collaboration problem such as poor communication). Because teaming skills are so crucial for success in the engineering profession, this concept is reinforced continuously in English class activities and essay topics.

Another concept that is developed in both classes is that of ethics. For one English essay assignment, students are asked to consider how the NSPE Code of ethics was or was not applied to the development of an engineering product. In this project, students review the code, then choose a well-documented topic such as the Hyatt Regency Floor failure or the Ford Pinto gas tank explosions. After researching, students then determine which ethical canons were adhered to and which were ignored. This assignment clearly connects ethical values in rhetoric such as goodness, honor, and expediency with the ethics of professional engineers, and also demonstrates the consequences of ignoring professional standards.

Related to ethics, the concept of decision making is linked between the engineering and English classes. Since effective decision making is so crucial in writing and engineering, various methods such as the Occam's Razor $^{8}$ heuristic and the Kepner-Tregoe Decision Analysis matrix ${ }^{9}$ are taught in both classes. These decision-making tools are considered when students develop their NSPE Code of Ethics paper. Students contextualize and explore how using the simplest approach, Occam's Razor, may work as a tool in engineering decisions. From their textbooks, they learn that to apply Occam's Razor means to strip away unnecessary elements so that the real 
problem can emerge. However, when this tool is placed alongside such works as the NSPE code of ethics, students see that elements that may appear unnecessary to a decision or design change may, in fact, be vitally necessary if the decision is to be ethical. Likewise, with the KepnerTregoe Decision Analysis method, students consider how decisions can be made by using a numerical matrix to score a course of action. The values that influence decision making using either of these decision-making tools can then be compared to the ethical canons of the NSPE code, which gives students a deeper understanding of the complexities of the engineering profession.

Modeling is yet another concept shared between the two classes. In English, the connection to modeling is made when stages of the writing process are discussed. Subsequently, in their journal writing, students compare the writing stages of invention, organizing and drafting with the engineering concept of modeling. At other times, the English teachers have asked students to write a short paper that defines modeling and how the definition might vary from subject to subject. Modeling is also discussed when students write the team paper on the causal analysis of an engineering disaster. Because some failures occur due to problems in the modeling stage of a project, students are able to recognize the importance of the developmental stage of any product, be it an engineering design or a research paper.

\section{Conclusion}

As teachers in the FIPE program, we have found that English and engineering can be successfully integrated in a way that benefits the students in each class. By carefully constructing an English curriculum that deliberately uses the strategies, concepts, and ideas from engineering, we can help students overcome the notion that subject areas are separate notebooks on a shelf that never connect. Instead, they can see connections between subjects and areas of overlap and areas of difference. The idea that writing, for example, is dependent on audience and occasion begins to make sense and yet they see that the strategies they use to brainstorm, invent, and draft in writing their English assignments can also help them with their engineering projects. Although we have been unable to do formal comparisons of work produced by students in the integrated class with that of students in the traditional classes, we can offer some anecdotal evidence that student themselves feel that they benefit from this integrated class. Each semester, the university requires that students fill out an evaluation for each teacher. On the reverse side of the bubble sheet, students are encouraged to give written feedback. Comments captured from the integrated class suggest that the students see value in this approach. At the end of the semester, many note that they understand the culture of engineering better, see why writing is such a vital part of an engineer's work, and understand how engineers need to use rhetoric as much as any other writer.

\section{Bibliography}

1 Florman, S., The Introspective Engineer. St. Martins, New York: (1996) p. 4.

2 http://www.eas.asu.edu/ asufc/

3 http://www.asu.edu/clas/english/writingprograms/teacherresources/policies.htm

4 Winsor, D. A. , Writing Like an Engineer: A Rhetorical Education, Yahweh, New Jersey: (1996) p.8. Bizzell, P., Academic Discourse and Critical Consciouness, University of Pittsburgh, Pittsburgh: (1992) p. 222.

5 For a complete set of assignments please visit the following webpage: http://www.public.asu.edu/ atsjd/fipe

6 Crowley, S. \& Hawhee, D., Ancient Rhetorics for Contemporary Students. Allyn \& Bacon, Boston: (1999) p.58.

Proceedings of the 2001 American Society for Engineering Education Annual Conference \& Exposition Copyright (C)2001 American Society for Engineering Education 
7 Voland, Gerald, Engineering by Design. Addison-Wesley, Reading, MA: (1999)

8 Starfield, A. M., Smith, K. A., \& Bleloch, A. L. How to Model It: Problem Solving for the Computer Age, Burgess Publishing, (1994), p. 18.

9 Fogler, S. H. \& LeBlanc, S., Strategies for Creative Problem Solving, Prentice Hall, Englewood Cliffs: (1995) p. 98.

\section{SARAH DUERDEN}

Sarah Duerden is a lecturer in Rhetoric and Composition in the English Department at Arizona State University. She received her PhD. in English in 1992 and her MA in English in 1986 from Arizona State University. She earned her BA in English at Sheffield University. She currently teaches in the Freshman Integrated Program for Engineering (FIPE) and also teaches Professional Writing, Academic Writing, and First-Year Composition.

\section{JEANNE GARLAND}

Jeanne Garland is an instructor in Rhetoric and Composition in the English Department at Arizona State University. She received her MA in Rhetoric from New Mexico State University, and she worked as a technical writer for the Engineering Research Center at New Mexico State University. She currently teaches in the Freshman Integrated Program for Engineering (FIPE) and also teaches Professional Writing, Technical Editing and First-Year Composition courses

\section{CHRISTINE HELFERS}

Christine Helfers is an instructor in Rhetoric and Composition in the English Department at Arizona State University. She received her MA in Rhetoric from Arizona State University in 1992. She currently teaches in the Freshman Integrated Program for Engineering (FIPE) and also teaches Persuasive Writing, Reflective Writing and First-Year Composition courses.

\section{RONALD ROEDEL}

Ronald Roedel is a professor in the Department of Electrical Engineering at Arizona State University. He received his Ph. D in Electrical Engineering in 1976 from UCLA and his BSE in Electrical Engineering in 1971 at Princeton University. He currently teaches in the Freshman Integrated Program for Engineering (FIPE) as well as graduate classes in Electrical Engineering. He also carries out research in the area of semiconductor materials and devices. He is the ASU Parents' Association Professor of the Year for 1999-2001. 